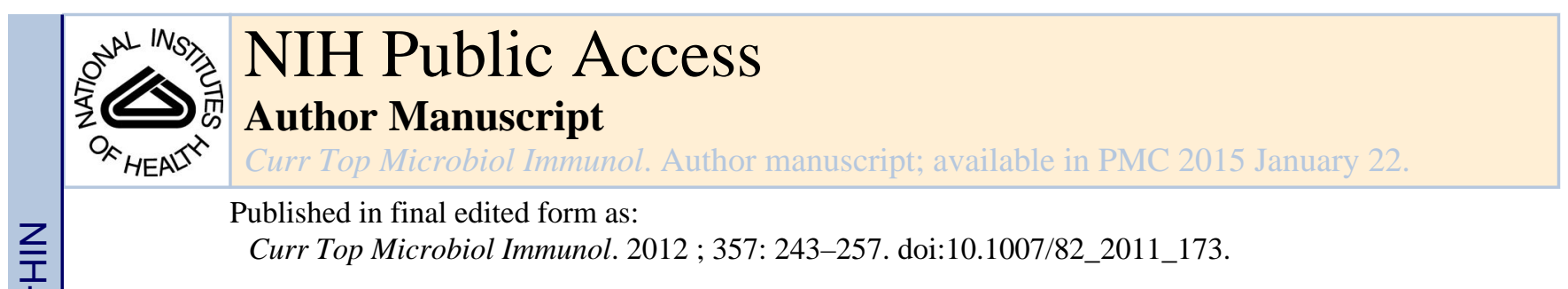

\title{
Animal Models of Ricin Toxicosis
}

Chad J. Roy,

Tulane National Primate Research Center, Tulane School of Medicine, New Orleans, LA 70112, USA

Kejing Song,

LSU Health Sciences Center, Children's Hospital, New Orleans, LA 70118, USA

Satheesh K. Sivasubramani,

Tulane National Primate Research Center, Tulane School of Medicine, New Orleans, LA 70112, USA

Donald J. Gardner, and

NIAID Rocky Mountain Laboratories, Hamilton, MT 59840, USA

Seth H. Pincus

LSU Health Sciences Center, Children's Hospital, New Orleans, LA 70118, USA

Chad J. Roy: croy@tulane.edu; Satheesh K. Sivasubramani: ssiua@tulane.edu

\section{Abstract}

Animal models of ricin toxicosis are necessary for testing the efficacy of therapeutic measures, as well studying the mechanisms by which ricin exerts its toxicity in intact animals. Because ricin can serve as a particularly well-characterized model of tissue damage, and the host response to that damage, studies of the mechanisms of ricin toxicity may have more general applicability. For example, our studies of the molecular mechanisms underlying the development of ricin-induced hypoglycemia may help elucidate the relationship of type II diabetes, insulin resistance, and inflammation. Studies in non-human primates are most relevant for testing and developing agents having clinical utility. But these animals are expensive and limited in quantity, and so rodents are used for most mechanistic studies.

\section{Introduction}

Ricin toxicosis is not a disease, per se. However it has a distinct pathogenesis, and animal models of ricin toxicosis allow us to study this. It is important to define mechanisms of pathogenesis to develop effective countermeasures. Ricin is also an excellent experimental model for studying the effects of local or systemic assaults on tissue integrity. The timing and route of the insult are known precisely. As described here, our studies of the mechanisms of ricin pathogenesis have surprising relevance for conditions seemingly unrelated toxin activity.

(C) Springer-Verlag Berlin Heidelberg 2011

Correspondence to: Chad J. Roy, croy@tulane. edu. 
In this chapter, we will describe the effects of ricin administered to animals systemically, orally, or via inhalation. It is clear that the toxic doses, clinical effects, and laboratory abnormalities are strictly governed by the route of administration. Nevertheless, there are common mechanisms and effects as well, including systemic release of proinflammatory cytokines resulting in subsequent inflammation, lymphoid depletion both locally and systemically, and loss of mucosal integrity at sites of challenge. Unique effects include massive fluid accumulation in lungs following aerosol exposure, and lethal hypoglycemia following systemic administration. Oral ingestion of ricin toxin in mice is only toxic in extremely high doses. If true in primates, this finding would alleviate concerns regarding contamination of the food and water supply with ricin as a means of terrorism.

Key to study mechanisms of ricin pathogenesis is the ability to localize the toxin in tissues. In our animal studies, we have utilized two methods: immunohistochemical localization and quantitative antigen capture ELISA with picogram sensitivity (Fig. 1). This ELISA uses two high affinity anti-ricin Abs, one to the A chain and the other to the B (Maddaloni et al. 2004), and thus assays for intact holotoxin. In the sections below, we will describe the pathologic effects and pathogenic mechanisms observed following systemic, oral, and aerosol administration of ricin in mice and macaques. We will focus on our own work, but will cite that of others as well.

\section{Systemic Administration}

Perhaps the most famous use of ricin as a bioweapon involved the injection of ricin, via a BB injected from a spring-loaded umbrella tip, in the assassination of the Bulgarian counterspy, Georgi Markov. At least 5 other suicides and murders have been attributed to injection of ricin (Audi et al. 2005; Schep et al. 2009). Nevertheless systemic administration of ricin is not considered to be a bioterrorism concern. Animal models that utilize injected ricin have generally been used to test the efficacy of therapeutic agents (Maddaloni et al. 2004; Pincus et al. 2002; Roche et al. 2008) rather than to study the pathophysiology of ricin toxicosis. But surprisingly, studies using injected ricin may inform our understanding of the relationship between inflammation, diabetes, and insulin resistance.

A parenteral injection of a lethal dose of ricin $(10 \mu \mathrm{g} / \mathrm{kg})$, via the intravenous or intraperitoneal route, results in the development of profound hypoglycemia, which appears to be the lethal event (Pincus et al. 2002). Remarkably no other blood chemistry abnormalities, other than a mild decrease in amylase, are observed during this time period (Pincus et al. 2002). Depending upon the route and dose of ricin, death occurs 12-36 h following the administration of ricin. In as yet unpublished studies, we examined the molecular mechanisms responsible for hypoglycemia. The results are summarized below.

Hypoglycemia is accompanied by an increase in circulating insulin, suggesting that hypersecretion of insulin may lead to the hypoglycemia. But paradoxically, we have observed a large decrease in insulin signaling in the liver as the hypoglycemia and hyperinsulinemia develop. Ketosis is also seen, indicating that tissues are starved of glucose. A rapid and marked increase in the size of pancreatic islets, most likely resulting from hypertrophy of beta cells, accompanies this metabolic state. This expansion in islets seems 
correlated with increased rates of insulin secretion, but we do not know if this is the driving factor in the hypertrophy. There is also altered expression of developmentally regulated pancreatic transcription factors. If healthy mice are given streptozotocin, which selectively kills insulin-secreting pancreatic beta cells, blood glucose levels rise as a result. If ricin is administered to these animals, blood glucose falls but not into the lethal range, unless a larger dose of ricin is used. Streptozotocin-treated mice do not make insulin (as expected), indicating that the ricin-induced drop in blood sugar is independent of insulin production. Streptozotocin-treated animals will still die, but 3-5 days following the ricin injection, and with normal or even elevated blood sugar levels.

A striking downregulation in the expression of glucose-6-phosphatase (G6P) in the liver is observed within $2 \mathrm{~h}$ of ricin administration. G6P catalyzes the final step in gluconeogenesis and glycogenolysis resulting in the release of free glucose. A genetic deficiency of G6P results in Glycogen Storage Disease, type I (Von Gierke's Disease), whose cardinal manifestation is fasting hypoglycemia. It is likely that this downregulation of G6P is the cause of the hypoglycemia seen after ricin administration. Because there is an early spike in circulating TNF-alpha within $1 \mathrm{~h}$ of ricin injection, and it has been shown that this cytokine can diminish G6P expression via activation of NF-kB (Grempler et al. 2004), we surmise that TNF-alpha is the proximate cause of the hypoglycemia we observe. In this regard, the pathogenesis of the ricin toxicosis may be similar to that of endotoxemia, in which TNFalpha is released and hypoglycemia occurs (Grempler et al. 2004; Yamamoto and Akira 2010). Systemic administration of pseudomonas exotoxin A has also been shown to cause TNF-alpha release, but no hypoglycemia has been reported (Chiu et al. 2009; Schümann et al. 1998). But with both endotoxin and pseudomonas exotoxin A, severe hepatic destruction is observed, whereas in ricin toxicosis, hypoglycemia precedes hepatic damage. In the initial hours following systemic injection of ricin, toxin is initially found associated with circulating red cells, but this drops rapidly by $6 \mathrm{~h}$. At the same time, there is a profound depletion $(<90 \%)$ of splenic lymphocytes, but not macrophages. Ricin accumulates in the liver and pancreas, peaking at 6-12 h. The pathologic effects resulting from the tissue binding of ricin, and systemic lymphoid depletion are not known.

These data demonstrate the close relationships between acute inflammation and glucose metabolism. Convincing data show a strong relationship between chronic inflammation and the development of type II diabetes. Both type II diabetes and the disorder of glucose homeostasis associated with ricin toxicosis are both associated with insulin resistance. But the two conditions have very different outcomes: hypoglycemia following ricin, hyperglycemia in diabetes. A significant difference in these responses is the marked and rapid development of beta-cell hyperplasia following ricin toxicosis. The development of methods to increase beta-cell activity has long been a goal of diabetes research.

\section{Oral Ingestion}

Contamination of food or water is considered to be a likely route by which a bioterrorist attack against civilians would be launched (Audi et al. 2005; Holtermann 2006; Schep et al. 2009). It is therefore surprising that there are no published reports describing animal studies in which the animals were fed ricin by mouth. All studies published to date utilize gavage 
feeding, in which ricin is directly administered by tube into the stomach (He et al. 2010; Ishiguro et al. 1983, 1984, 1992; Jackson 1957; Yoder et al. 2007). The lethal dose of ricin by this route is reported as $15-35 \mathrm{mg} / \mathrm{kg}$, roughly $\times 1000$ higher than that observed for injection and inhalation, although one group indicates that in fasting animals, the lethal dose is significantly lower (Smallshaw et al. 2007). While this route does allow accurate dosing, gavage feeding bypasses the oral and esophageal mucosa, which are very sensitive to injury and are the first site of exposure during normal ingestion. The pathogenesis of ricin toxicosis following gavage feeding is discussed elsewhere in this monograph.

There are examples in humans regarding oral ingestion of castor beans, which can be lethal. But ingestion of the bean is considerably different than ingestion of the toxin (Audi et al. 2005; Schep et al. 2009). Ricin toxin is not released from the bean until it has been chewed, and digested. Release of toxin from beans is generally in the ileum or colon. To study the effects of oral ingestion of ricin, we therefore undertook ricin-feeding studies in mice. The results shown below represent the primary publication of this data.

Initial experiments, performed with water containing trypan blue, showed that mice whose water was withheld for 4-6 h, would drink from a pipette tip without regurgitation, even with ricin $(5-25 \mathrm{mg} / \mathrm{ml})$. Table 1 shows that mice given ricin by mouth were remarkably resistant to the toxic effects of ricin at doses up to $35 \mathrm{mg} / \mathrm{kg}$. At $100 \mathrm{mg} / \mathrm{kg}$ clinical effects, and death, were observed. At the highest doses of oral feeding, we cannot rule out the possibility of aspiration, since in some cases the mice appeared to resist the final portions of this large volume feeding, and aspiration of even $0.01 \%$ of the inoculum represents a lethal dose by that route. In contrast, presentation of the ricin by gavage resulted in significant toxicity at $35 \mathrm{mg} / \mathrm{kg}$. To determine whether the oral flora might be binding to the ricin, and thereby neutralizing its toxicity, we fed ricin to gnotobiotic mice at $35 \mathrm{mg} / \mathrm{kg}$. No toxicity was observed. We withheld food from the mice overnight, prior to ricin feeding, again without effect. It thus appears that ricin given orally is less toxic than when administered by gavage feeding. There are several possible explanations for this unexpected observation, including: (1) binding of ricin to endogenous microflora, although our data do not support this explanation, (2) binding of ricin to soluble salivary or mucosal protein(s) instead of cells; ricin binding to secretory IgA has been demonstrated (Mantis et al. 2004), and (3) inactivation or inhibition of ricin by salivary or mucosal factors, and/or 4. binding of ricin to undigested food in the stomach (Smallshaw et al. 2007).

Tissues from mice that were fed ricin were examined for evidence of pathological changes. There was minimal tissue pathology following either one or three doses of $35 \mathrm{mg} / \mathrm{kg}$. At 100 $\mathrm{mg} / \mathrm{kg}$, mucosal erosions, submucosal and intraluminal bleeding, dying cells, and PMN invasion were observed from the stomach to the colon (Fig. 2). There was also widespread lymphoid depletion. We also observed the presence of tissue damage in the nasopharynx, suggesting the possibility of aspiration of ricin into airways.

Tissue localization of ricin was studied. The data provide an explanation for why ricin is more toxic when administered by gavage, than when fed orally (Fig. 3). There was virtually no binding of ricin to the tongue or esophageal tissues, when examined at $1 \mathrm{~h}$ (Fig. 3), nor at earlier time points (not shown). In marked contrast, binding to the luminal surface of the 
stomach's mucosa was clear, although little epithelial binding was observed in the small intestine (Fig. 3), or lower bowel. But in all GI tissues from the stomach through the bowel, accumulations of ricin were observed lining the submucosal blood vessels and/or lymphatics (Fig. 3), suggesting that ricin enters the circulation from these portals. Measurement of ricin in tissues by Ag capture ELISA supports these results (not shown), although the levels of ricin in the small intestine are higher than in the stomach, at $1 \mathrm{~h} 10 \mu \mathrm{g} \mathrm{ricin/gm}$ of tissue in the small bowel versus $4 \mu \mathrm{g} / \mathrm{gm}$ in the stomach. Ricin could be detected in GI tissues for 24 h. We also measured ricin in the stool (Fig. 1), where it peaked at $24 \mathrm{~h}$, and remained measurable almost 7 days later. We tested the cytotoxic activity of ricin in the stool, and found that it retained its full biological effect.

These data indicate that oral ingestion of ricin in mice is remarkably non-toxic. Ingestion of large amounts of toxin $(100 \mathrm{mg} / \mathrm{kg})$ is required to cause tissue damage. To put this into perspective, a human would be required to drink approximately one liter of highly concentrated toxin to produce symptoms, if our findings can be directly applied to humans. However, the oral and esophageal mucosa of humans and mice have significant differences. In the mouse these mucosal sites are lined with stratified squamous epithelium which is keratinized in places, whereas in humans, and in non-human primates, the epithelium is less protected. It is therefore essential that feeding studies be performed in non-human primates, whose oral and esophageal mucosa resemble ours. Taste aversion studies can also be performed in these animals. Although mice did not provide evidence for taste aversion, castor oil, which in the past was frequently used as a medicinal purgative, is notoriously foul tasting. If it is found that ricin is only marginally toxic in primate species or if the taste markedly limits their willingness to ingest ricin toxin, then concerns about ricin contamination of the food or water supply will be greatly eased.

\section{Respiratory (Aerosol) Exposure}

Ricin toxin is exquisitely toxic by the respiratory route as evidenced by the exceedingly low lethal and effective dose limits for experimentally-exposed laboratory species, such as mice and nonhuman primates. In mice, the lethal dose ranges between 1 and $3 \mu \mathrm{g} / \mathrm{kg}$, and in nonhuman primates is estimated at $5-15 \mu \mathrm{g} / \mathrm{kg}$, corresponding to body burdens of approximately 20-60 ng and 15-60 $\mu \mathrm{g}$, respectively (Franz and Jaax 1997). This is an exceedingly small mass of protein in the context of aerosol delivery, and our own results confirm these early estimates of lethal dose.

Inhalation of aerosolized ricin is considered the route of exposure most likely to result in serious health effects (Departments of the Army, the Navy, and the Air Force, and Commandant Marine Corps 2000). To provide some context for the potential threshold dose of ricin toxicity in man, given the absence of any clinical data that describes effects from an accidental or deliberate inhalation of the toxin, we offer the following. If the mass of a single $1 \mu \mathrm{m}$ particle (within the respirability range for pulmonary deposition) is approximately $5.2 \times 10^{-19} \mathrm{mg}$; approximately $7.0 \times 10^{9}$ particles containing $10 \%$ by weight of ricin would theoretically be a lethal dose of aerosolized ricin in a $70 \mathrm{~kg}$ man. An aerosol cloud of micron-sized particles containing high concentrations of ricin toxin, even in the event of significant atmospheric dilution, could deliver a potentially lethal dose to victims in 
a military battlefield or civilian terrorist scenario. Droplets of $1 \mu \mathrm{m}$ diameter will reach the distal lung tissue, whereas larger $(10 \mu \mathrm{m})$ droplets do not (Roy et al. 2003). Smaller particles persist in the environment longer: $<1 \mu \mathrm{m}$ remain airborne for long periods, $3-5 \mu \mathrm{m}$ remain aerosolized for less than an hour, and $<10 \mu \mathrm{m}$ fall out almost immediately. To produce particles $<3 \mu \mathrm{m}$ requires some degree of technical proficiency. The capacity to use drypowder formulations containing ricin would only compound the relative mass that could be potentially delivered by this modality of exposure, and the potential for mass casualties would increase. Inhalation of ricin toxin is not a natural route of exposure nor does exposure happen as a result of some industrial process or infection (e.g. wool sorting and inhalation anthrax). Yet the possibility of ricin being used nefariously as an aerosol is a very real threat.

There are no recorded clinical cases of human poisonings with aerosolized ricin; all of the reported poisonings with ricin or ricin-containing materials have been through injection or oral ingestion of castor beans. In the absence of clinical data, we have used nonhuman primates for studies to calculate a lethal dose in a humans. The interspecies susceptibility to ricin intoxication is remarkably close; one must assume that humans share at least some of this susceptibility to ricin intoxication by aerosol delivery.

A number of rodent species, including mice and rats, have been used in the aerosol model of ricin intoxication. Mice have been the rodent model of choice for pathogenesis, therapeutics, and vaccine efficacy studies. Inhalation of relatively low doses of ricin $(1-3 \mu \mathrm{g} / \mathrm{kg})$ in mice causes lung damage quickly, with pathological changes evident approximately $12 \mathrm{~h}$ postexposure, with the majority of the damage restricted to the lung (Griffiths et al. 2007). Animals succumb to intoxication between 1 and 3 days postexposure, usually from severe intra-alveolar edema and inflammatory exudate (Wong et al. 2007a, b). Ultrastructurally, initial signs of ricin-induced damage, predominantly observed in alveolar macrophages and bronchial epithelial cells, are seen as early as $6-12 \mathrm{~h}$ postexposure. Studies with radiolabeled ricin indicated high levels of the toxin throughout the respiratory system, with exceedingly low accumulation in liver, spleen, kidney, heart, testis, thymus, and blood. This finding reinforces that the lung is the major site of toxin action, when inhalation is the modality of exposure.

The histopathology of inhalation of sub-lethal doses of ricin in murine model shows that the development of lesions and establishment of damage was associated with the onset of pulmonary edema accompanied by the infiltration of inflammatory cells and hemorrhage (Benson et al. 2011). Inhalational exposure of rats showed that a diffuse necrotizing pneumonia of the airways develops, characterized by interstitial and alveolar inflammation and edema (Brown and White 1997). Inflammatory cells and total protein increase, suggesting that a significant portion of the fluid is exudate. This response is characteristic of pulmonary inflammation. The toxin also induces a generalized inflammatory response characterized by dose dependant increases of serum cytokine/chemokines that included TNF-a, IL-6, IL1 $\beta$, CXCL1, and CCL2 (Korcheva et al. 2007; Wong et al. 2007a, b). Microarray of lung and spleen indicates upregulation of genes associated with defense processes, response to pathogen, innate immune response, and inflammatory/stress response. Both these analyses suggest that route-specific exposure (intratracheal instillation) may 
produce a specific response in terms of cytokine signaling. Thereafter, signs of vascular leak syndrome, characterized by alveolar flooding and extravascular lung water, are evident. The transudate from capillary leak compounds the fluid accumulation of the inflammatory exudate. Arterial hypoxemia and acidosis develop as fluid accumulates.

Immunohistochemical analysis of the tissue shows ricin binds to ciliated bronchiolar lining cells, alveolar macrophages, and alveolar lining cells (Brown and White 1997).

Initial studies of aerosol exposure in five macaques were reported by Wilhelmsen and Pitt at USAMRIID (Wilhelmsen and Pitt 1996). Two animals receiving 21 and $27 \mu \mathrm{g} / \mathrm{kg}$ of ricin survived for $48 \mathrm{~h}$ and were sacrificed. Three others receiving $36.5,41.8$, and $36.6 \mu \mathrm{g} / \mathrm{kg}$, died at 48,36 , and $40 \mathrm{~h}$, respectively. Pathological examination revealed that all monkeys had widespread purulent pneumonia, diffuse necrosis, and acute inflammation of airways. They found alveolar flooding, with peribronchial edema. All monkeys also had inflammation of the trachea and pleura, and had purulent mediastinal lymphadenitis. Two animals had bilateral adrenocortical necrosis.

In experiments we performed, aerosols are generated directly into the head-only chamber using a Collison three-jet nebulizer (BGI Inc., Waltham, MA) operated at 18 PSIG, equating to a flow of $7.51 \mathrm{p} . \mathrm{m}$. and producing $3.0 \mathrm{E}+04$ particles/cc. The generator produces particles with a mass median aerodynamic diameter (MMAD) of $1.0 \mu \mathrm{m}$. Air samples are obtained during the exposure for measurement of ricin. Dilution air is drawn into the system at 8.51 p.m.; the total inhalation system flow rate is maintained at 16.01 p.m. Whole body plethsymography (WBP) is performed immediately prior to aerosol exposure as a predictive measure of respiration in order to estimate inhaled dose. The anesthetized primate is placed in a plexiglass sealed box, with only the head protruding from a latex rubber dam. The animal is allowed to breathe room air while volumetric changes of the thoracic cavity are measured in the sealed box. The box, outfitted with a pneumotachograph (Type "O", A. Fleisch Equipment, Switzerland), is connected to a low-range differential pressure transducer (Model DP45-14; Validyne Engineering, Northrigde, CA). The transducer is connected to a preamplifier wired to an A/D converter (Buxco Electronics, Sharon, CT). The WBP system is managed by commercial software (Biosystem XA for Windows, Buxco) running on a personal computer. After plethysmography is performed, the monkey is transported into the Class III BSC. After positioning the animal on the plexiglass bed in dorsal recumbency, the head is inserted into the exposure chamber. The aerosol exposure system is initiated using fully automated management control system. The aerosol challenge procedure is acute (single exposure) and short in duration $(10 \mathrm{~min})$. The respiration of the animal is measured during the exposure in order to calculate the dose received. At completion of the procedure, the animals head is removed from the chamber and wiped clean of any residual aerosol to avoid fomite production in post-aerosol transport back to the animal room for observation. The concentration of ricin to which the primate is exposed is calculated using protein measured in the sample taken during the aerosol challenge. Using the exposure concentration, the actual inhaled dose is determined by multiplying the empirically determined aerosol exposure concentration ( $\mu \mathrm{g} / \mathrm{l}$ air) in the chamber by the amount of air that was estimated (via results of WBP) to have been breathed by the primate during the exposure. Vital signs of macaques are measured by telemetry throughout the experiment. 
Animals show outward clinical signs of intoxication including depression, shortness of breath, and anorexia as early as $12-16 \mathrm{~h}$ postexposure. Fever develops within $24 \mathrm{~h}$. The clinical status of the animals continues to worsen, with an identifiable rapid decline $30 \mathrm{~h}$ postexposure. Moribund animals meeting pain assessment guidelines are euthanized to minimize any suffering that may have been experienced by the animal. Death or euthanasia are primarily due to respiratory failure, generally occurring $35-40 \mathrm{~h}$ post exposure. We have performed a "staircase" or "up and down" probit analysis (Dixon 1965) to determine that the $\mathrm{LD}_{50}$ in macaques for aerosol ricin is $5.8 \mu \mathrm{g} / \mathrm{kg}$ (Table 2). Pathologic examination of the lungs reveals findings similar to those described by Wilhelmsen. Grossly, the lungs were edematous and congested. There was extensive fibrinous pneumonia throughout the lung tissue accompanied by a necrotizing lymphadenitis. Other organ systems were also affected, although none were as severe as what was observed grossly in the lung. The liver, kidney, and small intestines were congested although little histologic changes were shown throughout these organ systems. Histologically (Fig. 4), the lung showed extensive localized damage in the form of inflammation-associated edema and necrosis. Alveolar flooding and massive fluid accumulation is apparent at necropsy of exposed primates, wet lung weights are generally double of what is considered normal (40 vs. $80 \mathrm{~g}$ ). These findings suggest that the cause of death was respiratory failure due to fluid accumulation in the lungs. In animals surviving aerosol exposure to ricin at sublethal doses (Table 2), lung damage is still significant +21 days postexposure (Fig. 5). The fibrinous accumulation in the lung was present in most animals surviving aerosol exposure to ricin. This material is part of the longterm tissue response to the acute injury resulting from ricin-induced inflammation, edema, and bronchioalveolitis. It would be expected that the long-term lung function of survivors of exposure to inhaled ricin would be greatly diminished from extensive fibrosis resulting from acute lung injury.

\section{Conclusions}

Animal models of ricin toxicosis are necessary for testing the efficacy of therapeutic measures, as well studying the mechanisms by which ricin exerts its toxicity in intact animals. Because ricin can serve as a particularly well-characterized model of tissue damage, and the host response to that damage, studies of the mechanisms of ricin toxicity may have more general applicability. Studies in non-human primates are most relevant to clinical utility, but these animals are expensive and limited in quantity, and so rodents are used for most mechanistic studies.

The effect of ricin administration is directly related to the route of administration. Nevertheless, there appear to be some common mechanisms, including rapid proinflammatory signaling, and a systemic plus local response. Aerosol exposure to ricin results in rapid accumulation of fluid in the lungs, leading to respiratory failure. Systemic signs and symptoms are also present in macaques following aerosol exposure. On the other hand, systemic exposure to ricin causes death by hypoglycemia. And it is unclear whether it is possible to cause death, or even morbidity, by the oral administration of ricin toxin alone. While it is clear that oral ingestion of castor beans can be lethal, the bean acts as a "timedrelease" capsule for the toxin, allowing its release in the lower bowel, where it causes more damage. 
Ricin is considered an important biodefense concern, primarily because of its easy availability, simple methods of purification, and its chemical stability. Systemic administration of ricin is not a viable bioterror threat, although it has already proven to be a tool of murder. If studies in non-human primates validate findings in mice that oral ricin is not particularly toxic, or tastes so bad that it would be detected immediately, then contamination of the food or water supply with ricin, heretofore a major biodefense concern for civilian populations, is no longer a worry. Aerosol exposure to ricin could occur in a battlefield setting, where an enemy could use sophisticated aerosolization procedures to make submicronsized aerosol droplets. There is also risk of aerosol exposure in civilian populations. But because the means of producing appropriate sized aerosol particles requires some degree of technical sophistication, dispersal of the ricin and mass casualties are unlikely (Schep et al. 2009).

\section{Acknowledgments}

The authors would like to acknowledge the research veterinarians, animal handling technicians, and the aerobiology technicians who performed the studies described. The authors would also like to acknowledge the expert pathological analysis of macaque tissues by Dr. Peter J. Didier, TNPRC, and mouse tissues by Dan Long of RML. SP and KS: U54 AI057156, Western Regional Center of Excellence for Biodefense and Emerging Infectious Disease Research R01 AI059376. Children's Hospital of New Orleans DG: NIAID intramural funds CJR: NIH/ NCRR P51 RR000164, DSTL/Ministry of defense.

\section{References}

Audi J, Belson M, Patel M, et al. Ricin poisoning: a comprehensive review. JAMA J Am Med Assoc. 2005; 294:2342-2351.

Benson JM, Gomez AP, Wolf ML, et al. The acute toxicity, tissue distribution, and histopathology of inhaled ricin in Sprague Dawley rats and BALB/c mice. Inhal Toxicol. 2011; 23(5):247-256. [PubMed: 21473711]

Brown RFR, White DE. Ultrastructure of rat lung following inhalation of ricin aerosol. Int J Exp Pathol. 1997; 78:267-276. [PubMed: 9505938]

Chiu C-C, Chen HH-C, Chuang H-L, et al. Pseudomonas aeruginosa exotoxin A-induced hepatotoxicity: an animal model in rats. J Vet Med Sci. 2009; 71:1-8. [PubMed: 19194069]

Departments of the Army, the Navy, and the Air Force, and Commandant Marine Corps. Field manual: treatment of biological warfare agent casualties. Army FM 8-284. 2000 Available online at http:// www.army.mil/usapa/doctrine/8_Series_Collection_1.html.

Dixon WJ. The up-and-down method for small samples. J Am Stat Assoc. 1965; 60:967-978.

Franz, DR.; Jaax, NK. Chapter 32: Ricin Toxin. In: Sidell, FR.; Takafuji, ET.; Franz, DR., editors. Medical aspects of chemical, biological warfare. Washington, DC: Office of the Surgeon General of the Army; 1997. p. 631-642.

Grempler R, Kienitz A, Werner T, et al. Tumour necrosis factor alpha decreases glucose-6phosphatase gene expression by activation of nuclear factor kappaB. Biochem J. 2004; 382:471479. [PubMed: 15167811]

Griffiths GD, Phillips GJ, Holley J. Inhalation toxicology of ricin preparations: animal models, prophylactic and therapeutic approaches to protection. Inhal Toxicol. 2007; 19:873-887. [PubMed: 17687718]

He X, Mcmahon S, Henderson TD, et al. Ricin toxicokinetics and its sensitive detection in mouse sera or feces using immuno-PCR. PLoS ONE. 2010; 5:e12858. [PubMed: 20877567]

Holtermann, K. Response to a ricin incident: guidelines for federal, state, and local public health and medical officials; 2006. p. 1-88.http://www.bt.cdc.gov/agent/ricin/hp.asp 
Ishiguro M, Mitarai M, Harada H, et al. Biochemical studies on oral toxicity of ricin. I. Ricin administered orally can impair sugar absorption by rat small intestine. Chem Pharmacol Bull. 1983; 31:3222-3227.

Ishiguro M, Harada $\mathrm{H}$, Ichiki O, et al. Effects of ricin, a protein toxin, on glucose absorption by the rat small intestine. (Biochemical studies on oral toxicity of ricin. II). Chem Pharmacol Bull. 1984; 32:3141-3147.

Ishiguro M, Tanabe S, Matori Y, et al. Biochemical studies on oral toxicity of ricin. IV. Fate of orally administered ricin in rats. J Pharmacobio-Dyn. 1992; 15:147-156. [PubMed: 1494977]

Jackson JH. Tissue changes in alimentary canal of mouse induced by ricin poisoning. J Physiol. 1957; 135:30-31. [PubMed: 13406758]

Korcheva V, Wong J, Lindauer M, et al. Role of apoptotic signaling pathways in regulation of inflammatory responses to ricin in primary murine macrophages. Mol Immunol. 2007; 44:27612771. [PubMed: 17257680]

Maddaloni M, Cooke C, Wilkinson R, et al. Immunological characteristics associated with protective efficacy of antibodies to ricin. J Immunol. 2004; 172:6221-6228. [PubMed: 15128810]

Mantis NJ, Farrant SA, Mehta S. Oligosaccharide side chains on human secretory IgA serve as receptors for ricin. J Immunol. 2004; 172:6838-6845. [PubMed: 15153502]

Pincus SH, Eng L, Cooke CL, et al. Identification of hypoglycemia in mice as a surrogate marker of ricin toxicosis. Comp Med. 2002; 52:530-533. [PubMed: 12540166]

Roche J, Stone M, Gross L, et al. Post-exposure targeting of specific epitopes on ricin toxin abrogates toxin-induced hypoglycemia, hepatic injury, and lethality in a mouse model. Lab Invest. 2008; 88:1178-1191. [PubMed: 18779782]

Roy CJ, Hale M, Hartings JM, et al. Impact of inhalation exposure modality and particle size on the respiratory deposition of ricin in BALB/c mice. Inhal Toxicol. 2003; 15:619-638. [PubMed: 12692733]

Schep LJ, Temple WA, Butt GA, et al. Ricin as a weapon of mass terror-separating fact from fiction. Environ Int. 2009; 35:1267-1271. [PubMed: 19767104]

Schümann J, Angermüller S, Bang R, et al. Acute hepatotoxicity of Pseudomonas aeruginosa exotoxin A in mice depends on T cells and TNF. J Immunol. 1998; 161:5745-5754. [PubMed: 9820556]

Smallshaw JE, Richardson JA, Vitetta ES. RiVax, a recombinant ricin subunit vaccine, protects mice against ricin delivered by gavage or aerosol. Vaccine. 2007; 25:7459-7469. [PubMed: 17875350]

Wilhelmsen CL, Pitt ML. Lesions of acute inhaled lethal ricin intoxication in rhesus monkeys. Vet Pathol. 1996; 33:296-302. [PubMed: 8740703]

Wong J, Korcheva V, Jacoby DB, et al. Intrapulmonary delivery of ricin at high dosage triggers a systemic inflammatory response and glomerular damage. Am J Pathol. 2007a; 170:1497-1510. [PubMed: 17456757]

Wong J, Korcheva V, Jacoby DB, et al. Proinflammatory responses of human airway cells to ricin involve stress-activated protein kinases and NF-kappaB. Am J Physiol Lung Cell Mol Physiol. 2007b; 293:L1385-L1394. [PubMed: 17873006]

Yamamoto M, Akira S. Lipid A receptor TLR4-mediated signaling pathways. Adv Exp Med Biol. 2010; 667:59-68. [PubMed: 20665200]

Yoder JM, Aslam RU, Mantis NJ. Evidence for widespread epithelial damage and coincident production of monocyte chemotactic protein 1 in a murine model of intestinal ricin intoxication. Infect Immun. 2007; 75:1745-1750. [PubMed: 17283086] 

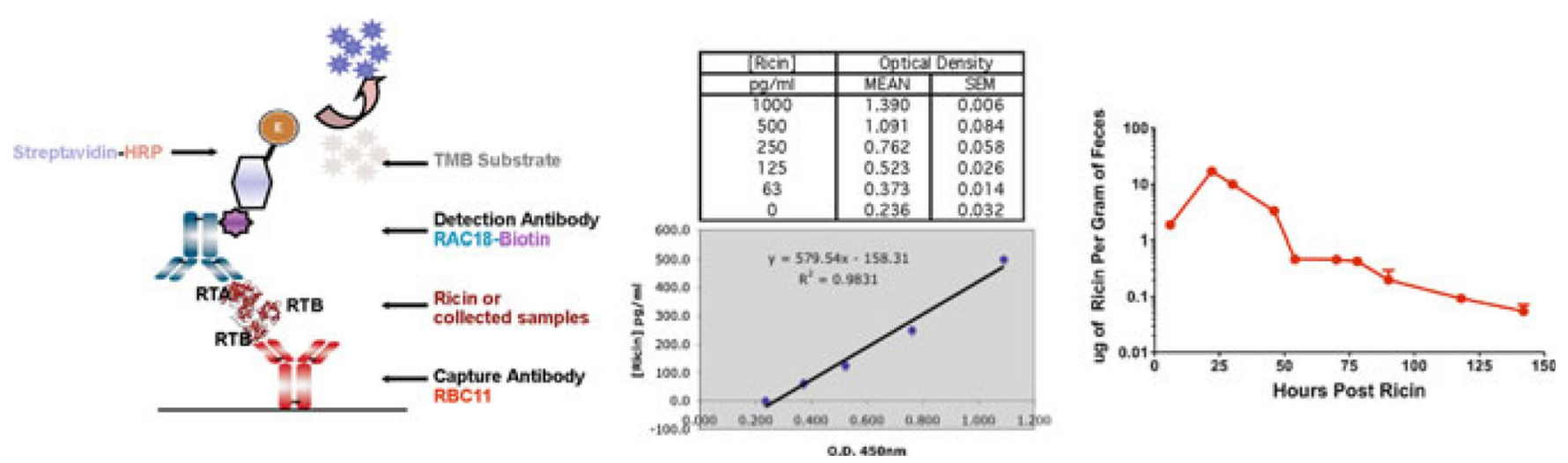

Fig. 1. Antigen capture ELISA for detection of ricin in biological specimens

This triptych shows a schematic of the assay (left), standard curves obtained (center), and the presence of ricin in feces with time following an oral feeding of $35 \mathrm{mg} / \mathrm{kg}$ of ricin to mice (right). The vertical axis shows $\mu \mathrm{g}$ ricin/gm of feces, mean and SEM; the horizontal is time post feeding in hours. Ricin holotoxin can be detected in the feces almost a week post feeding 

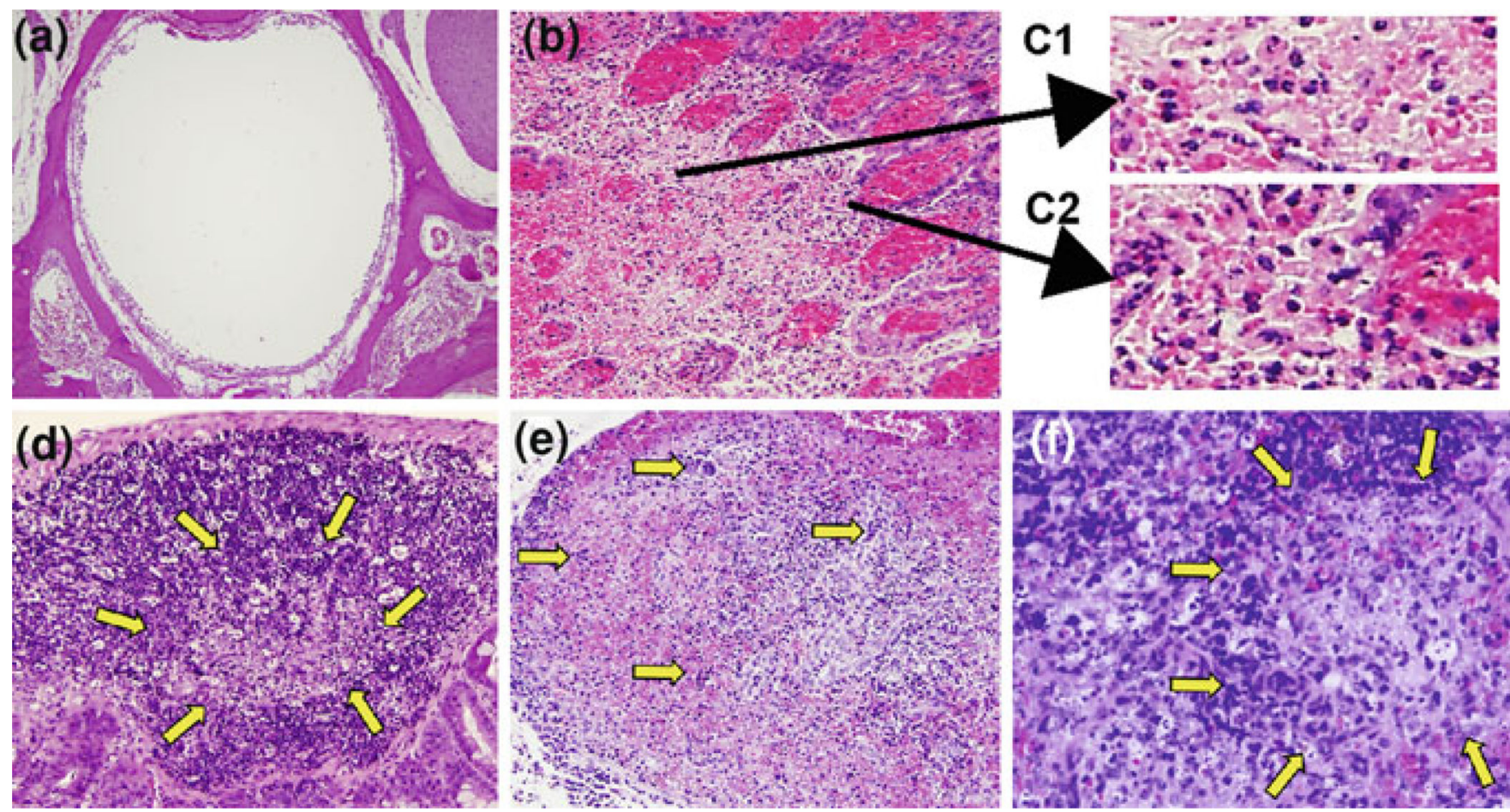

Fig. 2. Local and distant pathological findings 24-72 following oral feeding of a lethal dose (100 $\mathrm{mg} / \mathrm{kg}$ ) of ricin

a Nasopharynx showing hemorrhage, diffuse epithelial necrosis, and inflammation. b

Duodenum with marked submucosal hemorrhage, loss of mucosal integrity flanked by dying cells (shown in greater magnification in panel $\mathbf{c} 2$ ), and with luminal accumulations of apoptotic/necrotic cells and PMNs (expanded in $\mathbf{c 1}$ ). d GALT in the ileum showing marked areas of hypocellularity (arrows surround the largest). e Mesenteric lymph node with hemorrhage, marked hypocellularity, and nests of dying cells (arrows). f Spleen showing hypocellularity (arrows), dying cells, and hemorrhage 

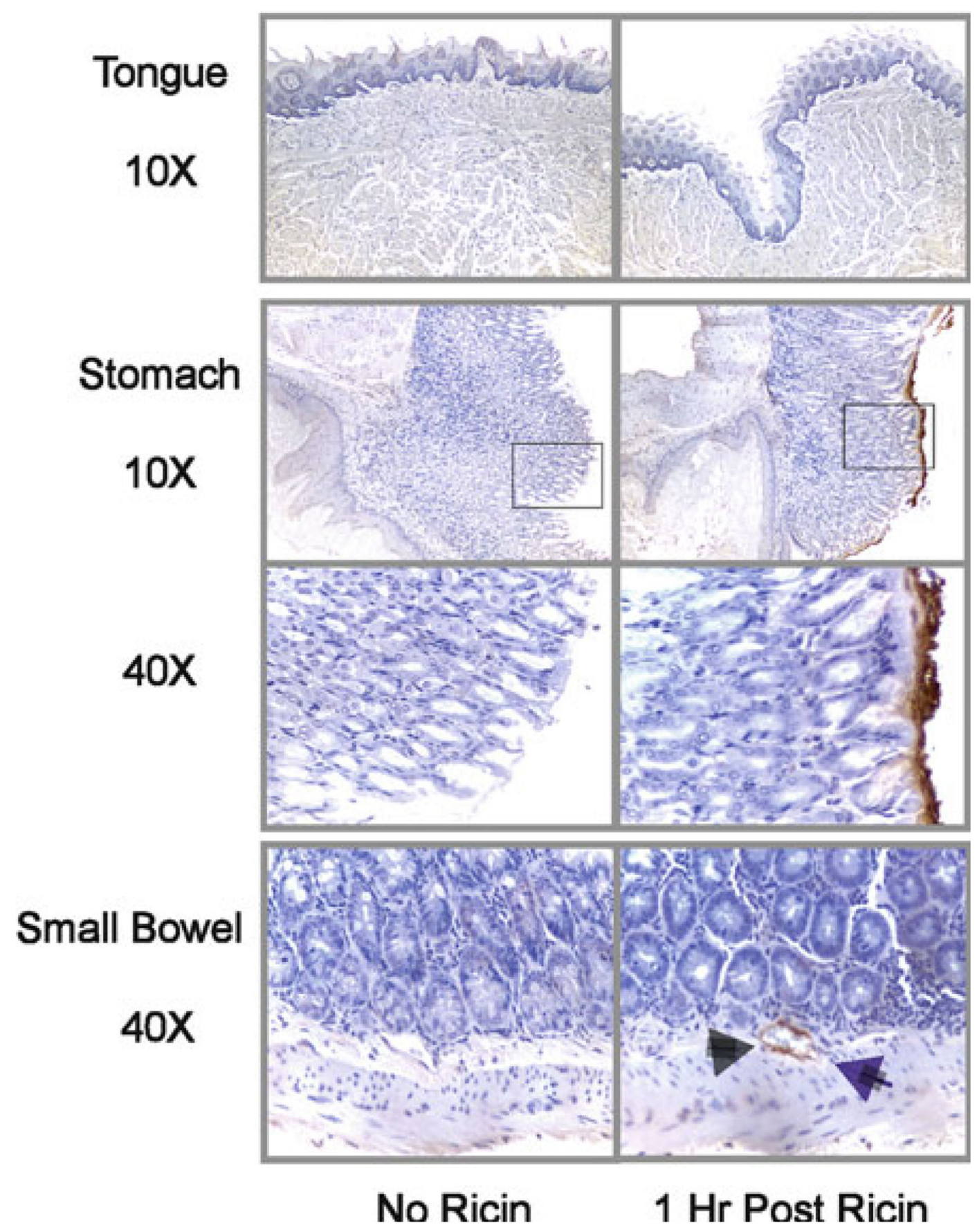

Fig. 3. Immunohistochemical localization of ricin following feeding

Mice were fed ricin and sacrificed $1 \mathrm{~h}$ later. Ricin was detected in tissues using a panel of four monoclonal antibodies detecting different epitopes on ricin A and B chains. Tissues from mice not exposed to ricin (left) are compared to those obtained $1 \mathrm{~h}$ post feeding (right). The presence of ricin is indicated by the reddish-brown color, and by the arrows in the lowest panel. The magnification of the objective used when the photograph was taken is indicated on the left. In micrographs of the stomach, the squares in the micrographs taken with the $\times 10$ objective represent the fields shown at $\times 40$ 

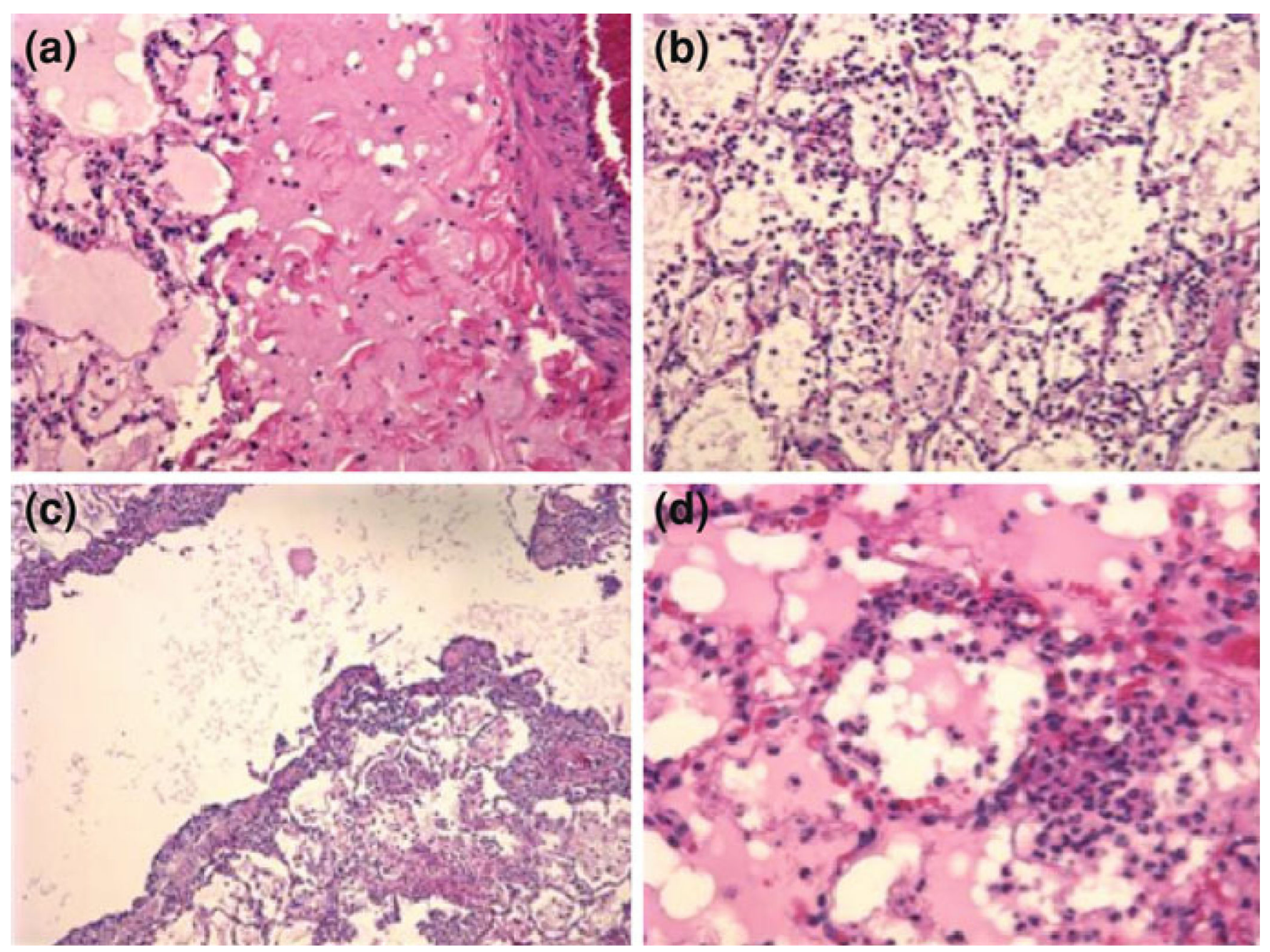

Fig. 4. Histopathology of ricin-exposed lung

Hematoxylin and eosin stained microscopic images from the lung of an animal that died following exposure to aerosolized ricin. a Severe perivascular and alveolar edema $(\times 20$ objective); b suppurative fibrinous pneumonia $(\times 20)$; $\mathbf{c}$ bronchiolar necrosis $(\times 10)$; $\mathbf{d}$ severe alveolar edema and numerous neutrophils $(\times 40)$ 

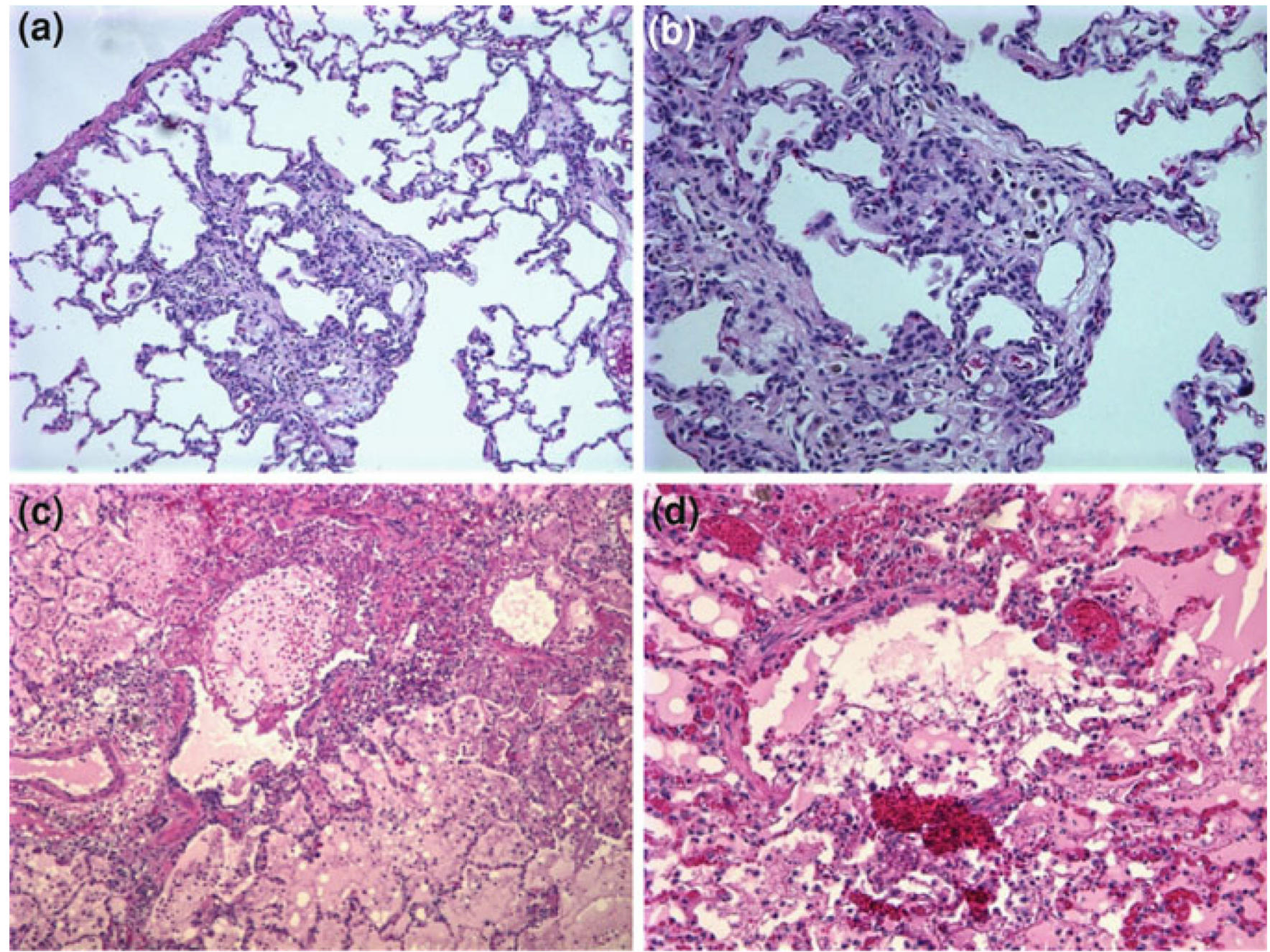

Fig. 5. Lung histopathology of macaques exposed to ricin by aerosol

Hematoxylin and eosin stained microscopic images from two animals exposed to ricin by aerosol. The tissue sections shown in $\mathbf{a}$ and $\mathbf{b}$ were from animal 02 that survived challenge and was euthanized at day 21 postexposure. The micrographs show moderate to severe focal or multifocal fibrosis. The sections in $\mathbf{c}$ and $\mathbf{d}$ are from animal 05 that died $+45 \mathrm{~h}$ postexposure. $\mathbf{c}$ shows fibrinosuppurative and necrotizing bronchitis/bronchiolitis with surrounding alveolar edema, fibrin and inflammation, $\mathbf{d}$ severe necrotizing bronchiolitis with accompanying edema 


\section{Table 1}

Effects of oral administration of ricin

\begin{tabular}{llll}
\hline Dose $(\mathbf{m g} / \mathbf{k g})$ & Route & Clinical signs $^{\boldsymbol{a}}$ & Mortality \\
\hline $5-17.5$ & P.O. & $0 / 30$ & $0 / 30$ \\
35 & P.O. & $0 / 64$ & $0 / 64$ \\
$35 \times 3$ & P.O. & $0 / 6$ & $0 / 6$ \\
100 & P.O. & $2 / 8$ & $2 / 8$ \\
30 & Gavage & $21 / 24$ & $16 / 24$ \\
\hline
\end{tabular}

${ }^{a}$ Clinical signs include ruffled coat, lethargy, decreased feeding, weight loss 


\section{Table 2}

$\mathrm{LD}_{50}$ for aerosol exposure to ricin in macaques, determined by "up and down" analysis

\begin{tabular}{lrrl}
\hline Animal ID & $\boldsymbol{\mu g}$ total & $\boldsymbol{\mu g} / \mathbf{k g}$ & Outcome \\
\hline AN01 & 23.0 & 4.4 & Died \\
AN02 & 15.4 & 1.9 & Survive \\
AN03 & 51.5 & 5.2 & Survive \\
AN04 & 36.0 & 3.4 & Survive \\
AN05 & 102.9 & 13.7 & Died \\
AN06 & 51.0 & 11.3 & Died \\
AN07 & 27.4 & 4.5 & Survive \\
AN08 & 29.8 & 4.8 & Died \\
LD $_{50}$ estimate $=5.8 \mu \mathrm{g} / \mathrm{kg}$ & & & \\
\hline
\end{tabular}

Crown copyright DSTL 2011. DSTL/JA58369. Published with the permission of the defense science and technology laboratory on behalf of the controller of HMSC 